December - 2009

\title{
Editorial
}

\section{IRRODL Year in Review}

\section{Terry Anderson}

Editor

The end of the calendar year with its seasonal celebration of the winter solstice, Diwalhi, Eid alAdha, Christmas, Hanukkah, New Year's and many secular feasts and parties brings moments of both celebration and of thankfulness. We are very pleased to be celebrating IRRODL's most successful year to date. In this our tenth year we published our now normal three general issues, and we also released special regional issues on Africa and the Middle East and a special topical issue on Openness and the Future of Higher Education. This level of production has meant a great deal of reviewing, formatting, revision, and editorial oversight. I am very grateful to everyone who has contributed to IRRODL this year. Many of you have reviewed more than a single paper, seven scholars have served as guest editors, we have a new book review editor, and Ms. Brigette McConkey has had to learn the publishing game, at a new workplace, while working at record speed. We also upgraded to a new version of the Open Journal System, which provides a number of enhancements "under the hood" and will allow us to incorporate more interactive elements as the year unfolds. Additionally, we began to publish our articles in epub format, which allows their use on portable phones and on e-book readers. I hope you agree that the results of this year's publication have made all of our efforts worthwhile.

My hope is that each IRRODL reader, editor, reviewer, and contributor is able to look backwards at a fulfilling year of learning and achievement. Further, it is our hope that you face the upcoming year with confidence, energy, and excitement for the opportunities we have to enhance teaching, learning, and distance education research throughout the world.

In this issue, we present eight research articles, one article from the field, a book review, and the links to some recent Canadian Institute for Distance Education Research webcasts. The first article, Rory McGreal's Case Study of an International E-Learning Training Division, features a review of the Commonwealth of Learning's (COL) e-training section. COL undertakes a variety of activities and programs, which makes an overall evaluation of its disparate programs challenging. In this article both the accomplishments and the barriers yet to be overcome are clearly articulated. Although it may seem self-serving, we are very pleased to be publishing the results of Olaf Zawacki-Richter, Eva Maria Baecker, and Sebastian Vogt's Review of Distance Education Research (2000 to 2008): Analysis of Research Areas, Methods, and Authorship Patterns. During the eight years covered by the review of the five major DE journals, IRRODL 
published the most articles, and it was the most international of the journals (authors from outside the country of journal publication) Also, it had the second highest number of references per article. As well, the authors found that 6 of the 39 most prolific authors are associated with Athabasca University. So besides reading to discover what a wonderful journal IRRODL is $;$, there is much to learn from this article about the type and methodology of distance education scholarship.

The third article attempts to quantify the amount of time students spend reading conference forums. Asynchronous threaded discussion forums remain the mainstay of online distance education, and thus understanding how much time is required and expected in reading this important component of online distance education is important. Abbie Brown and Tim Green's Time Students Spend Reading Threaded Discussions in Online Graduate Courses provides a necessary understanding of a major determinant of the effectiveness and efficiency of online learning. The fourth article adds insights relating to the now quite familiar community of inquiry model. Zehra Akyol, D. Randy Garrison, and M. Yasar Ozden's Online and Blended Communities of Inquiry: Exploring the Developmental and Perceptional Differences explores the differences between students' perceptions of purely online and blended learning contexts using the COI survey instrument, transcript analysis, and interviews. Next, George Veletsianos and Irene Kleanthous provide A Review of Adventure Learning. Adventure learning allows online and classroom students to travel with explorers, scientists, and other role models, allowing virtual participation in many of the most exciting and important activities on our planet. The authors identify results, models, further research opportunities, and challenges for those engaged in this motivating type of distance education. The last research article details the challenges of delivering science education at a distance to large numbers of students. Arundhati Mishra, Vijayshri and Suresh Garg's Evaluation of an Undergraduate Physics Programme of Indira Gandhi National Open University: A Case Study helps us to realize the challenges and the opportunities afforded by distance education in meeting the large and growing needs for quality educational opportunity throughout the world.

The Field Notes section contains an article that provides an overview of Athabasca University's new Doctorate of Education program. Dorothy (Willy) Fahlman writes in The First Doctoral Program in Distance Education in North America from the perspective of one of the students in the first cohort of this program. The explosion of interest in and practice of distance education around the globe means we need an ever-growing supply of quality DE researchers, teachers, and scholars. Non-resident, part-time programs such as the one described by Fahlman are critically important in meeting this need.

Our best for a relaxing yet invigorating holiday, and we hope to find you reading and contributing to IRRODL in the new year.

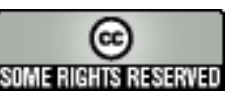

